\title{
Apuntes sobre el problema de las contaminaciones en los textos en prosa*
}

\author{
Cesare Segre \\ Accademia dei Lincei
}

Título: Apuntes sobre el problema de las contaminaciones en los textos en prosa.

Resumen: A partir de las conclusiones extraídas del análisis de la tradición del Bestiare d'Amours de Richart de Fornival, el presente artículo aspira a fijar un decálogo de coordenadas útiles a la hora de enfrentarse a la edición de textos en prosa de la época prehumanística (y aun después).

Palabras clave: Bestiare d'Amours, Richart de Fornival, Contaminación, Prosa prehumanística.

Fecha de recepción: 26/11/2016.

Fecha de aceptación: 26/12/2016.
Title: Notes about the Problem of Contamination in Prose Texts.

Abstract: According to the conclusions drawn from the analysis of the tradition of the Bestiare d'Amours by Richart de Fornival, this paper aims to establish a decalogue of useful coordinates in order to edit prose texts of the Prehumanistic period (and even after).

Key words: Bestiare d'Amours, Richart de Fornival, Contamination, Prehumanistic Prose.

Date of Receipt: 26/11/2016.

Date of Approval: 26/12/2016.

A continuación, presento, de forma axiomática, el resultado de algunas personales, y por tanto limitadas, experiencias ecdóticas. Estas derivan en gran parte del estudio dedicado a la tradición del Bestiare d'Amours de Richart de Fornival. Es muy poco frecuente hallar contaminaciones cuando se examinan textos italianos en prosa del siglo XIII. Y esta observación

* Traducción de Linda Garosi (Universidad de Córdoba). Creneida agradece a la Profesora Maria Luisa Meneghetti, viuda del maestro Cesare Segre, su gentileza a la hora de otorgar su nihil obstat para el traslado y la difusión de este trabajo por la piel de toro. 
despierta cierto interés, en tanto que indicio de una labor filológica menos vital y organizada en comparación con la de la Francia del Doscientos (me refiero a la gran habilidad empírica de los maestros de los scriptoria). Existe una hermosa simetría — que tal vez no haya sido apreciada por los interesados - entre la actividad prehumanística de Richart y las complejas contaminaciones de las que fue objeto su obra maestra.

1. Una metodología de las contaminaciones podrá fijarse de forma más sencilla estudiando las tradiciones en las que también existen códices sin contaminar. Es evidente que siempre que se conozcan las localizaciones de partida tanto de los errores como de las lecciones singulares en los grupos y subgrupos originarios, dispondremos de una base segura para examinar la confluencia sucesiva, evitando caer así en la trampa de las meras conjeturas, correcciones e hipercorrecciones. Considérese asimismo que unas contaminaciones capaces de introducir en un texto base solamente lecciones correctas, o que se estimen como tales, son muy raras en la Edad Media. En algunos casos, a lo sumo, se podrá creer que el grado de intensidad del cotejo fue inversamente proporcional a la 'fiabilidad' que se le reconocía a un texto.

2. La contaminación de ejemplares no puede ser analizada del mismo modo que las demás y, por tanto, no atañe a nuestro discurso: cuando un copista, o para completar un ejemplar incompleto, o porque ha encontrado un ejemplar más fácil de leer o con más autoridad, transcribe alternativamente a partir de dos ejemplares, su copia pertenece, alternativamente, solo a uno de los grupos de procedencia de los dos ejemplares.

3. La contaminación de lecciones es la consecuencia de un cotejo realizado en el testimonio del que haya derivado el códice. Esta contaminación se puede clasificar, según sus modalidades, como: a) contaminación simple (fruto de un único cotejo con un único ejemplar); b) contaminación fraccionada (resultado de varios cotejos sucesivos con un único ejemplar); y c) contaminación múltiple (a partir de una serie de cotejos con más de un ejemplar), que también puede ser fraccionada.

En virtud del mayor o menor grado de intensidad del cotejo también se podrían distinguir tres clases: a) contaminación esporádica (las lecciones extraídas del segundo ejemplar son ocasionales y aisladas); b) contaminación densa (las lecciones se cifran no solo en palabras aisladas, sino 
en grupos de palabras u oraciones, a menudo introducidas en el primer ejemplar); c) contaminación completa (se da cuando el que realiza el cotejo quiso reproducir todas las diferencias entre sus dos ejemplares). La clasificación, de acuerdo con estos diversos grados de exhaustividad, es por supuesto menos categórica que la primera. Sin embargo, creo que puede tener cierta utilidad cuando se ponga en relación con el eje de los errores y de las variantes características, puesto que este no queda mermado en exceso por las contaminaciones esporádicas, mientras que, en cambio, sí que resulta gravemente desviado, y hasta quebrado, por la contaminación densa o completa.

4. La identificación de un códice contaminado trae consigo, fácilmente, la identificación de otros códices contaminados. De hecho, mientras que el cotejo sencillo también puede ser labor de un estudioso o de un amateur, la transcripción de un códice cotejado es casi siempre (antes del Humanismo, durante el cual los propios filólogos ejercerán de copistas o acometerán transcripciones) indicio de la labor de un scriptorium: el códice contaminado nos lleva, pues, hacia un epicentro de la tradición manuscrita. Si el scriptorium poseía dos o más ejemplares de un mismo texto, raramente se preparaba a partir de estos una edición ne varietur; era frecuente, en cambio, el caso de contaminaciones múltiples o fraccionadas; como también lo era ese otro en que, con ocasión de transcripciones sucesivas, aquel que en un primer momento se había empleado como segundo ejemplar continuara haciendo las veces de ejemplar base y viceversa (contaminación cruzada). Tras determinar, entonces, los grupos de pertenencia de los ejemplares en el haber o salidos de un scriptorium, a menudo sucede que, en los códices que allí se produjeron, los rasgos singulares de tales grupos se presentan con proporciones y con modalidades diferentes.

5. Las contaminaciones se incrementan con la difusión de una obra. Y esto ocurre porque: a) aumenta la posibilidad de que se puedan reunir en un mismo scriptorium distintos ejemplares de la misma; b) aumentan las probabilidades de que los códices usados durante el proceso de contaminación estuvieran, ellos mismos, ya contaminados; c) quien efectúa los cotejos se percata necesariamente de que las diferencias entre los ejemplares se acentúan.

6. Existe un nexo entre contaminación y refundición: diríase que, mientras que la contaminación esporádica corresponde a un intento de 
fidelidad, la contaminación densa o múltiple da la sensación de algo relativo, ya que invita a alcanzar, con medios autónomos, una fluidez siquiera aparente: el copista se convierte, de buscador, en creador de variantes. Por consiguiente, cuando ejemplares perdidos muy antiguos han contribuido a la contaminación, la confianza en sus representantes contaminados tiene que ser contrarrestada por un severo juicio acerca de las posibles conjeturas y refundiciones posteriores.

7. A medida que se desciende de contaminaciones simples a contaminaciones múltiples, y por ello de contaminaciones esporádicas a contaminaciones completas, disminuye la posibilidad de comprobar, con una serie cerrada de cotejos puntuales, los vínculos de derivación. Este hecho puede ser considerado en parte como consecuencia del punto 5); no obstante se puede añadir, con carácter más general, que: de acuerdo con las características del grupo $a$, al que pertenece el ejemplar base, y con las del grupo $b$ (más, eventualmente, $c, d \ldots$ ) del segundo ejemplar, multiplicándose o enredándose la contaminación, el sistema de los elementos característicos de $a$ resulta cada vez más ofuscado, mientras que los elementos procedentes de $b$ (más, eventualmente, $c, d \ldots$ ) no se organizan nunca en un sistema a causa del ínsito carácter de libertad del cotejo.

De ello se deduce que los indicios válidos para el análisis de las contaminaciones simples y esporádicas (por ejemplo, las lagunas, las lecciones añadidas, etc.), siempre útiles y, a la vez, susceptibles de más depuraciones (por ejemplo: un códice A contaminado con un códice B presentará muy probablemente, en lugar de lagunas de su familia $a$, la lección de $\mathrm{B}$; un códice $\mathrm{A}$ contaminado con un códice $\mathrm{B}$ presentará, de nuevo muy probablemente, en lugar de lagunas de su grupo $a$, las lecciones de B desplazadas respecto a su colocación originaria; y así sucesivamente), no son sin embargo suficientes.

8. De aquí la propuesta de un análisis estadístico de las variantes. Un análisis extremadamente delicado: a) porque, evidentemente, habría que prescindir de la distinción entre errores y variantes equipolentes; b) porque, por consiguiente, todo quedaría sujeto al peligro de tomar en consideración emparejamientos debidos a afinidades regionales y culturales, y no tanto a relaciones directas. Obsérvese, por otra parte, que, a causa de lo apuntado en el parágrafo 6), la falta de un error característico puede muy a menudo, dada la especial naturaleza de la contaminación, ser el 
resultado, también poligenético, de correcciones conjeturales.

Para una aplicación prudente del método estadístico se pueden, no obstante, sancionar algunas advertencias que convierten los resultados de un análisis estadístico de las variantes en algo más que fiable: se trataría, en resumidas cuentas, de una integración del análisis estadístico con los análisis puntuales ya en uso, o bien de análisis estadísticos planteados de otra manera. Mientras que el primer procedimiento no requiere mayores explicaciones, quisiera detenerme en el segundo un poco más.

9. El cotejo del que deriva la contaminación nunca es uniforme. Dividiendo pues el texto A en sectores convencionales, es obvio que los sectores en los que el sistema de la familia $a$ de origen esté mermado de forma más grave resultarán salpicados con un número superior de elementos del grupo $b$ (más $c, d \ldots$ ) del segundo ejemplar; los sectores en que los elementos del grupo $b$ sean más recurrentes, serán, a su vez, los más ricos en elementos del segundo ejemplar B. Si el segundo ejemplar ya estaba contaminado, la escasez en A de elementos de su grupo a y la frecuencia de las lecciones del grupo $b$ y de su representante $\mathrm{B}$, coincidirán con la presencia de lecciones de los grupos $c, d$... confluidos parcialmente en B; y si, al contrario, es A el códice que ya era resultado de una contaminación, las huellas de la primera contaminación seguirán un diagrama especular al de las huellas de la contaminación con B.

En el recurso a estos tanteos y a muchos más que, según las circunstancias, se pueden poner a punto, hay que tener presente otro hecho interesante: la inversión de las relaciones estadísticas consiguientes a las contaminaciones. En general, al ser los errores característicos más numerosos, cuanto más se desciende a lo largo de las ramas de la tradición manuscrita, en el manuscrito A contaminado con B estarán presentes más errores y lecciones características de $\mathrm{B}$ que errorres y lecciones características de su modelo $b$ (inversión de vínculos). Es un hecho que señalo aquí, y no en el primer párrafo de este apartado, porque está claro que para plantear la posibilidad de una contaminación valen más los errores de un grupo que los de su representante.

10. El estudio de los códices contaminados no solo satisface la legítima aspiración de ser exhaustivos o un afán por situar dentro de sus coordenadas históricas la tradición manuscrita, sino que a menudo permite recuperar la lección de códices perdidos e importantes por su autoridad, 
o incluso de arquetipos o redacciones del autor. Si se piensa que, en general, los códices tienen una descendencia más exigua cuanto más cercanos están al original; y que, en segundo lugar, para constituir una vulgata, se tiende a eliminar los testimonios aislados, los cuales a menudo son los más puros; y que, finalmente, la dignidad exterior de un códice, y por ende lo que lo hace idóneo para ser difundido, depende a menudo de la fortuna de la obra que se transcribe en él, y por tanto pertenece a un segmento cronológico relativamente lejano del punto de origen, por todo ello quedará patente la posibilidad de que alguna contaminación, especialmente si pertenece a una época bastante alta, represente la última huella de riachuelos de la tradición textual que se secaron enseguida: los códices «comerciales» contaminados conservarían las últimas palabras de ejemplares dotados de escasa vitalidad.

Formulo aquí esta posibilidad, en abstracto y con motivaciones provisorias, ya que solo se ha podido constatar en concreto para la tradición de los Bestiaire; sin embargo, estoy convencido de que se podrá volver a presentar si se amplían y perfeccionan los estudios de las contaminaciones. 